\title{
Analysis of the possibilities in railways shape assessing using GNSS mobile measurements
}

\author{
Wladyslaw Koc ${ }^{1}$, Cezary Specht ${ }^{2}$, Piotr Chrostowski ${ }^{1, *}$, and Jacek Szmagliński ${ }^{1}$ \\ ${ }^{1}$ Gdansk University of Technology, Faculty of Civil and Environmental Engineering, Poland \\ ${ }^{2}$ Gdynia Maritime University, Faculty of Navigation, Poland
}

\begin{abstract}
In recent years, a dynamic development of satellite positioning techniques using both static and mobile GNSS coordinates register mode can be observed. In addition, still developing Real-time GNSS Networks, post-processing algorithms and another measurement signal analysis algorithms, make the satellite measurements increasingly used in railway industry sector. In the article the possibilities which follows from the mobile satellite measurements in railway engineering are briefly presented. In the years 2009-2015, the authors conducted a series of field investigations on operated railway lines. The obtained results of these measurements led to the development of a number of algorithms that increase the range of applicability of GNSS measurements. The analysis of obtained results also showed how the accuracy of the measurements have increased since 2009. The achieved accuracy has been increased due to a development of GNSS positioning systems as well as improvement of the measurement methodology, i.e. configurations of satellite receivers and layouts of their placement on a mobile measuring platform. It was also found that the development of data analysis algorithms contributed to the increase in the obtained accuracy in assessment of a railway track axis shape. The authors indicate the possibilities of applying GNSS techniques at various stages of construction and operation of railways. According to the authors, the most important advantage of both the presented measurement technique and computational methodology is the ability to effectively and relatively low-cost data acquisition regarding the existing state of the railway line. These data can be successfully used to design changes to the geometry of railway lines, and therefore satellite positioning has enormous application potential in the process of modernization of operated railway lines.
\end{abstract}

\section{Introduction}

From the very beginning, the railway tracks were subjected to the evaluation of their shape due to the direct relation between the quality of the geometric layout and the safe and comfortable exploitation of the track. This is due to the fact that geometric parameters are unambiguously related to the kinematic parameters. The relations concern especially the admissible train speed as well as the displacements and transverse accelerations occurring on the rail vehicle. On this basis, simulation models of vehicle and track interaction are still being developed [1,2], and also new methods for mathematical and numerical description of the track axis are proposed $[3,4,5]$, as in case of road engineering - especially in case of highways design [6].

Additionally, there is an increasing need to be able to identify location of trains on the network (not only in case of High Speed Railways) in order to manage the capacity of the railway lines [7]. At the same time, the development of methods of tracks measurements and their evaluation can be observed $[8,9,10,11]$. Constantly, the classical methods of geodesy are developed, especially the methods using tacheometry $[12,13]$. This measurement technique is accurate and precise, although it requires a track-side geodetic reference network. It is worth noting, that this reference is nowadays commonly stabilized using GNSS techniques.

Alternative techniques for determining the shape of the track are based on a laser scanning. This measurement along with post-process algorithms allows to extract from the recorded cloud of points a virtual axis of the railway track with a high accuracy - few millimeters [14].

Diagnostic measurements are also used to assess track axis. This type of measurement is usually performed with a measurement trains (investigating of the unevenness of the track within the selected wave range) and provides a quasi-continuous signal. The signal after using appropriate calculation algorithms, enables the reconstruction of the track axis shape [15]. However, the accuracy of the geometric reconstructing process depends on the adopted calculation algorithms because the relations between deformed track shape and the measured versine is undefined. Usually, the unevenness measurements (chord-versine analysis) are used to a limited extent to identify the position of particular geometrical elements along the tested section of the track. The distribution of versines is qualitatively assessed and then, in relation to the model distribution of curvature, the location of segments with constant and variable curvature is identified [13].

Considering the above methods (especially the stationary ones) of the track axis reconstruction, it should be noted that the tracks are measured locally around the measuring device. Then, the observation results are made into a measuring sequence whose components are being matched one to each other. This results in additional measurement errors and growing uncertainty along with the length of the measurement section.

* Corresponding author: piochros@pg.edu.pl 
Another measurement technique that usually assists the major and prime technique for track axis measurement is the inertial technique INS [10]. The advantages of this technique are mainly due to the fact that the measurement signal is not related to any external reference system as for example in tacheometric or satellite measurements. But also in this case, the accuracy of position determination does not exceed the GNSS technique. However, in conjunction with satellite positioning (GNSS + INS), the obtained accuracy - especially in a low availability of high-quality satellite signal - is higher.

The authors over the period between 2009-2015 have conducted their research using the technique of mobile satellite measurements. The methodology of conducting measurements as well as algorithms using measured rectangular coordinates for evaluation and design of the track axis have been developed since then. Using the possibilities which follow from the GNSS techniques, a series of algorithms for evaluation and design support were developed $[5,16,17,18]$.

\section{Mobile satellite measurements method}

\subsection{Measurement system - assumptions}

The authors assumed that the measurement method should enable effective and accurate measurement of the position of the track axis. For this purpose, the team prepared a measuring system consisting of the measuring platform on which the receivers with controllers were mounted. The measuring set was moved along the track by the motor vehicle which was pulling or pushing the platform. The stable mounting of the measuring devices (antennas and controllers) was one of the most important issues of the measurement methodology. Different locations for antennas were tested, but ultimately it was decided that they should be placed exactly above the track axis. This was done by mounting the tribrach in the bogie pivots.

Different high class GNSS devices were used in the measurements. Table 1 presents measurement systems used in research in individual years. To increase the measurement efficiency, the measurement was carried out at the highest possible frequency - maximum $20 \mathrm{~Hz}$. The analysis of the measurement data led to the assumption that the distance between the measurement points should not be greater than $0.5 \mathrm{~m}$. Therefore, it was possible to carry out measurements with a maximum traveling speed of the measuring set of $35 \mathrm{kph}$. As it turned out, this speed was sufficient for the effective identification of the geometric layout of individual elements of the measured route.

To achieve the highest accuracy of measurement, only the measurements obtained in the carrier-phase with corrections coming from the reference stations were used in analysis $[19,20]$. The share of positions determined in the carrier-phase is presented in the table. 1. The ASGEUPOS RTN, LEICA SMART-NET RTN and the reference station located in the Gdansk University of Technology were used in the measurements.

\subsection{Measurement system - implementation}

The assumptions of the GNSS mobile positioning technique were first implemented by the authors in 2009 . In that time, $50 \mathrm{~km}$ of the railway line around Gdansk was measured. During the first measurements, the WM-15 motor car was used with the mounted two-axle PWM-15 platform car. Four Leica ATX 1230GG GNSS receivers were installed on the top of the platform car. The receivers were mounted directly above the rail tracks - over the wheelsets. In the following years, another arrangements of antennas were tested. The effect of this modifications on the reliability parameters of the measurement was analyzed. In 2010, the receivers were assembled in the symmetry axis of the platform in places above wheelsets. This time, the three GNSS receivers were assembled on two platform cars. In subsequent measurements performed in the same year the latest Leica Viva GS-15 receiver was used instead of one ATX receiver. Simultaneously the arrangement of antennas on platforms was changed. These changes allowed to test the influence of signal obstructions caused by the blocking of the sky by the WM-15 cabin. In 2012 the team initiated the measurements on tram tracks. Instead of the WM-15 power car, the N8C tram was used, and instead of twoaxle platform cars - the bogies from the 300 series pre-war tram were used. The Leica Viva GS-12 and GS-15 receivers were mounted on the bogie pivot. In the following years, an analogous scheme of the assembling of antennas on various types of rail and tram bogies was used. In 2015 the last so far series of measurements were made on a newly built railway line connecting Gdansk Wrzeszcz Station with the Gdansk Airport Station, i.e. at the Pomeranian Metropolitan Railway [21]. As many as 4 tram bogies and three sets of GNSS receivers were used: Leica Viva GS-15, Trimble R10 and Topcon Hiper Pro. The list of used measuring devices is shown in Figure 1 and described in table 1 . The changes in configuration and distribution of receivers carried out in subsequent years were aimed at determining the impact of the measurement methodology on the reliability of determining the position of the track axis. 


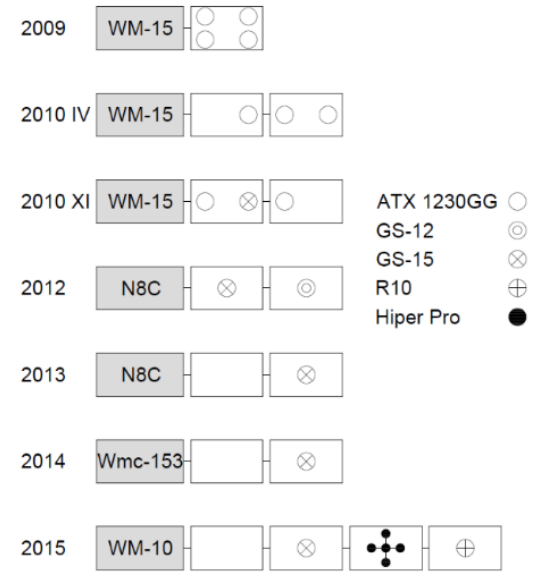

Fig. 1. Configuration of the measurement set in the following years.

Table 1. Parameters of the measurement system.

\begin{tabular}{|c|c|c|c|c|}
\hline & Distance & $\begin{array}{c}\text { GNSS } \\
\text { systems }\end{array}$ & RTN & Processing \\
\hline $\begin{array}{l}\text { Feb } \\
2009\end{array}$ & $\begin{array}{l}50 \mathrm{~km} \\
\text { Railway } \\
\text { line }\end{array}$ & GPS & $\begin{array}{c}V R S, F K P \\
\text { MAC, ASG- } \\
\text { EUPOS }\end{array}$ & $\begin{array}{c}\text { Real Time, } \\
\text { Service } \\
\text { NAVGEO } \\
\text { Distance auto- } \\
\text { recording } 30 \\
\text { cm, }\end{array}$ \\
\hline $\begin{array}{l}\text { Apr } \\
2010\end{array}$ & $\begin{array}{l}20 \mathrm{~km} \\
\text { Railway } \\
\text { line }\end{array}$ & GPS & $\begin{array}{c}\text { VRS, FKP, } \\
\text { MAC, ASG- } \\
\text { EUPOS }\end{array}$ & $\begin{array}{c}\text { Real Time, } \\
\text { Service } \\
\text { NAVGEO, } \\
\text { Distance auto- } \\
\text { recording } 30 \\
\text { cm, Leica } \\
\text { Office software }\end{array}$ \\
\hline $\begin{array}{l}\text { Nov } \\
2010\end{array}$ & $\begin{array}{c}60 \mathrm{~km} \\
\text { Railway } \\
\text { line }\end{array}$ & GPS & $\begin{array}{c}\text { VRS } \\
\text { service: } \\
\text { ASG- } \\
\text { EUPOS }\end{array}$ & $\begin{array}{c}\text { Real Time, } \\
\text { Service } \\
\text { NAVGEO, } \\
\text { Distance auto- } \\
\text { recording } 30 \\
\text { cm, Leica } \\
\text { Office software }\end{array}$ \\
\hline $\begin{array}{l}\text { Feb } \\
2012\end{array}$ & $\begin{array}{c}50 \mathrm{~km} \\
\text { Tram } \\
\text { network }\end{array}$ & $\begin{array}{l}\text { GPS/GL } \\
\text { ONASS }\end{array}$ & $\begin{array}{c}\text { FKP } \\
\text { Gdansk } \\
\text { University } \\
\text { of } \\
\text { Technology } \\
\text { Reference } \\
\text { Station }\end{array}$ & $\begin{array}{c}\text { Post- } \\
\text { processing, } \\
\text { Auto-recording } \\
\text { every } 30 \mathrm{~cm} \text {, } \\
\text { Leica Office } \\
\text { software }\end{array}$ \\
\hline $\begin{array}{c}\text { Oct } \\
2013\end{array}$ & $\begin{array}{c}30 \mathrm{~km} \\
\text { Tram } \\
\text { network }\end{array}$ & $\begin{array}{l}\text { GPS/GL } \\
\text { ONASS }\end{array}$ & $\begin{array}{c}\text { VRS } \\
\text { service: } \\
\text { Leica } \\
\text { SmartNet } \\
\text { GNSS } \\
\text { network } \\
\end{array}$ & $\begin{array}{c}\text { Real Time, } \\
\text { Auto-recording } \\
20 \mathrm{~Hz} \text { (Leica } \\
\text { GS 15), Leica } \\
\text { Office software }\end{array}$ \\
\hline $\begin{array}{l}\text { May } \\
2014\end{array}$ & $\begin{array}{l}18 \mathrm{~km} \\
\text { Narrow } \\
\text { gauge } \\
\text { railway } \\
\text { line }\end{array}$ & $\begin{array}{l}\text { GPS/GL } \\
\text { ONASS }\end{array}$ & $\begin{array}{c}\text { VRS } \\
\text { service: } \\
\text { Leica } \\
\text { SmartNet } \\
\text { GNSS } \\
\text { network } \\
\end{array}$ & $\begin{array}{c}\text { Real Time, } \\
\text { Auto-recording } \\
20 \mathrm{~Hz} \text {, Leica } \\
\text { Office software }\end{array}$ \\
\hline $\begin{array}{l}\text { Jun } \\
2015\end{array}$ & $\begin{array}{c}19 \mathrm{~km} \\
\text { Railway } \\
\text { line }\end{array}$ & $\begin{array}{l}\text { GPS/GL } \\
\text { ONASS/ } \\
\text { BeiDou }\end{array}$ & $\begin{array}{c}\text { VRS } \\
\text { services: } \\
\text { Trimble, } \\
\text { Topcon and } \\
\text { Leica } \\
\text { networks } \\
\end{array}$ & $\begin{array}{c}\text { Real Time, } \\
\text { Auto-recording } \\
20 \mathrm{~Hz} \text {, Trimble } \\
\text { Business } \\
\text { Center }\end{array}$ \\
\hline
\end{tabular}

\section{Assessment of results}

\subsection{Accuracy analysis - assumptions}

The comparative assessment concerned straight sections of railway and tram routes arranged on monotonous longitudinal inclinations. In such a geometric arrangement, the determination of the track axis basing on the measured coordinates is unambiguous mainly because there is no need to identify the distribution of curvature, and the measurement has no errors due to the existing of a cant in arcs. Thus, the only problem is the identification of the parameters of straight in a local coordinate system. For this purpose, a linear regression analysis of the measured coordinates was made. In their work, the authors analyzed main directions of the tracks using various algorithms, including the use of weighted regression [22, 23].

In this analysis, due to the different character of the measurements series carried out over the years, it was decided to use the common method of least squares.

The parameter which has being evaluated was the distance of the determined track axis from the model shape, i.e. from the least squares' straight line. Due to the nature of the rail vehicle movement along the usually deformed track, reminiscent of navigating sea vehicles, the authors used a navigation parameter describing a course error - XTE (Cross Track Error). XTE is defined as the shortest distance between the designated course line and the current position of the moving vehicle. Therefore, the analysis is performed in the local coordinates system ( $\mathrm{x}_{\text {loc }}, \mathrm{y}_{\text {loc }}$ ), whose abscissa axis coincides with the determined path direction. The graphic interpretation of the XTE parameter is shown in Figure 2.

A) Graphical interpretation of XTE

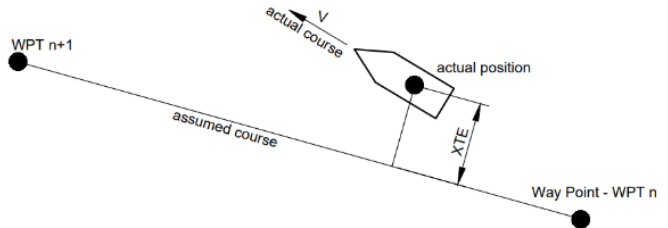

B) Adaptation of XTE for railway track assessment

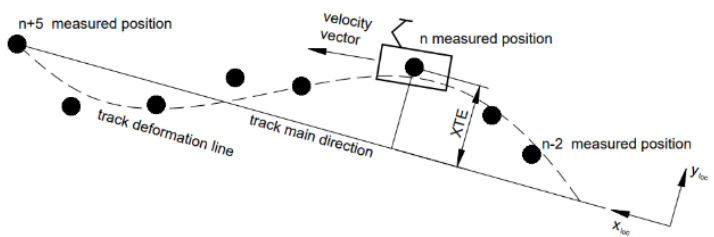

Fig. 2. Graphical interpretation of XTE parameter.

The method of determining the local coordinates consists in performing matrix operations. These matrix transformations are performed on homogeneous coordinates as shown in the following equations:

$$
(x, y) \rightarrow\left[\begin{array}{lll}
x & y & 1
\end{array}\right]
$$




$$
\left[\begin{array}{ccc}
x_{1}^{\prime} & y_{1}^{\prime} & 1 \\
x_{2}^{\prime} & y_{2}^{\prime} & 1 \\
\cdots & \cdots & \cdots \\
x_{n}^{\prime} & y_{n}^{\prime} & 1
\end{array}\right]=\left[\begin{array}{ccc}
x_{1} & y_{1} & 1 \\
x_{2} & y_{2} & 1 \\
\cdots & \cdots & \cdots \\
x_{n} & y_{n} & 1
\end{array}\right] \times \boldsymbol{M}
$$

where $\boldsymbol{M}$ is the transformation matrix of the form:

$$
\boldsymbol{M}=\left[\begin{array}{lll}
m_{11} & m_{12} & 1 \\
m_{21} & m_{22} & 1 \\
m_{31} & m_{32} & 1
\end{array}\right]
$$

To take into account deformations of the analyzed straight sections, the measurement signal was filtered in the wave numbers domain. For this purpose, a Fourier transformation (Fast Fourier Transformation) was performed, and then the threshold for cutting off the high wave numbers was determined. It results directly from the stiffness of the railway track structure, which cannot be deformed in any way. Fourier transform is represented by equation (4):

$$
X_{k}=\sum_{n=0}^{n=N-1} x_{n} e^{-\frac{2 \pi i}{N} n k}, k=0, \ldots, N-1
$$

where:

$$
\begin{aligned}
& X-\text { transformation result, } \\
& X \text { - signal's samples, } \\
& N \text { - number of samples which should be equal to } \\
& 2^{k} \text {, where } k \text { is a natural number. }
\end{aligned}
$$

The accurately determine the cut-off threshold, it requires extensive analysis of geometrical rails irregularities found on exploited railway and tram lines. For the purpose of this comparative analysis, a cut-off threshold was established basing on the field tests on the selected track section which was measured by the tachometric method. Finally, the cut-off value has been established as $f_{\text {lim }}=0.15 \mathrm{~m}^{-1}$. Since that moment, the XTE parameter has been calculated between the filtered measurement signal and the theoretical model of the straight section of constant vertical inclination.

In order to ensure an uniform assessment of measurement accuracy for all measuring series, an auxiliary parameter $|\triangle X T E|$ was defined - equation (5). This parameter is defined as the distance between the filtered measurement signal and the raw one. It can be therefore interpreted as an indicator of measurement uncertainty. Basing on the analysis of $|\triangle \mathrm{XTE}|$ parameter, the empirical statistical distributions as well as estimators of expected value and standard deviation were determined.

$$
\left|\Delta X T E_{i}\right|=\left|y_{-}^{\mathrm{f} i n t}{ }_{\text {loc }}\left(x_{\mathrm{loc}}\right)-y_{\text {loc }}^{\mathrm{r}}\left(x_{\mathrm{loc}}\right)\right|
$$

Where:

$y_{-}^{\mathrm{f} \text { int }}{ }_{\text {loc }}\left(x_{\text {loc }}\right)$ - the interpolated value of vertical coordinate of the filtered measurement signal in the local reference system

$y^{\mathrm{r}}{ }_{\text {loc }}\left(x_{\text {loc }}\right)$ - the value of vertical coordinate of the raw measurement signal in the local coordinate system.

\subsection{Accuracy analysis - results}

The analysis presented in this chapter concerns selected straight sections of measured tracks of constant vertical inclinations. The final selection was also made with respect to the quality of the received signal in both horizontal and vertical planes. The number of track sections selected for comparative analysis is presented in Table 2.

Table 2. The number of analyzed measurement sections.

\begin{tabular}{|l|c|c|c|c|c|c|}
\hline Date & 2009 & 2010 & 2012 & 2013 & 2014 & 2015 \\
\hline $\begin{array}{l}\text { Number of } \\
\text { test sections }\end{array}$ & 22 & 18 & 20 & 9 & 16 & 10 \\
\hline
\end{tabular}

The empirical distribution and statistics were determined for each of the selected sections. Sample histograms of the $|\triangle \mathrm{XTE}|$ parameter for the boundary years are shown in Figures 3 and 4 . The graphs show the values of statistics together with the numbers of investigated track sections. It is clear from the comparison of the two graphs, that the parameter $|\triangle \mathrm{XTE}|$ has statistically decidedly lower values in 2015. Certainly, this is due to the development of measurement technology based on the GNSS systems. The adoption of common criteria in the analysis made it possible to become independent of the geometrical condition of the analyzed railway lines - in 2015, the newly-constructed railway track was analyzed.

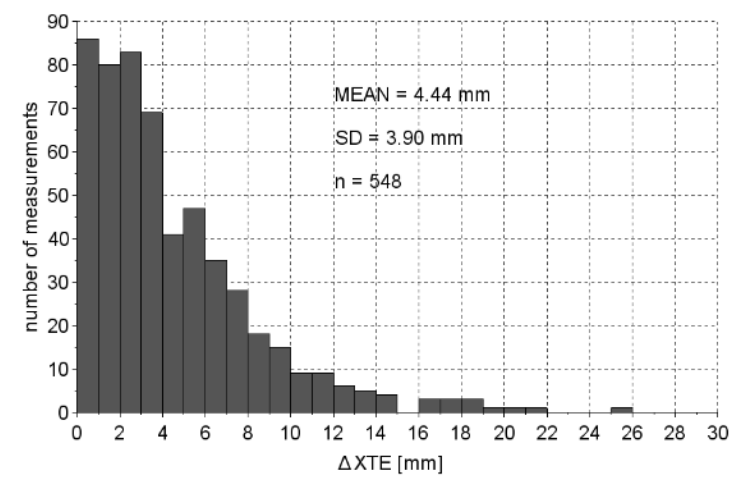

Fig. 3. Empirical distribution of $|\triangle X T E|$ for the selected test section in 2009.

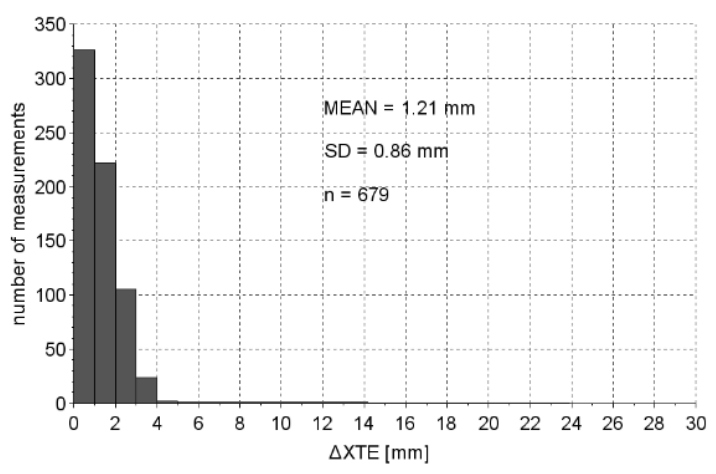

Fig. 4. Empirical distribution of $|\triangle \mathrm{XTE}|$ for the selected test section in 2015. 
In order to generalize the results with reference to particular years, the parameters of empirical distributions have been calculated for all test sections. The average values for particular years are presented in table 3. From these values a certain trend of increment in the measured mean $|\triangle X T E|$ can be noticed. To present an uncertainty, a standard deviation of the mean (for each year) has been also calculated. In 2009 the measurements were conducted in non-urbanized areas so the standard deviation of the mean is relatively low. The subsequent measurements concerned urbanized areas. Therefore in 2010 and 2012 the mean error was much higher. However, in next years the uncertainty was decreasing. So finally, the mean error in 2015 was approximately as low as in case of non-urbanized terrain in 2009 , but the mean $|\triangle \mathrm{XTE}|$ is significantly lower.

Table 3. A comparison of the mean $|\triangle X T E|$ and their uncertainties for the period 2009-2015.

\begin{tabular}{|c|c|c|}
\hline Year & $\begin{array}{c}\text { Mean value of } \\
\mid \Delta \text { XTE } \mid[\mathrm{mm}]\end{array}$ & $\begin{array}{c}\text { Standard deviation } \\
\text { of the mean } \\
\mid \Delta \text { XTE } \mid[\mathrm{mm}]\end{array}$ \\
\hline 2009 & 3.52 & 0.67 \\
\hline 2010 & 4.41 & 2.23 \\
\hline 2012 & 3.37 & 1.13 \\
\hline 2013 & 2.32 & 0.70 \\
\hline 2014 & 3.11 & 0.46 \\
\hline 2015 & 1.61 & 0.69 \\
\hline
\end{tabular}

\section{Application of the GNSS measurements for the track axis identification}

The growing accuracy of satellite measurements observed in recent years allowed to use them in the process of identifying geometric parameters of operated railway and tram lines. The authors developed a number of algorithms which makes it possible to describe the geometric layout of track in the rectangular coordinate system. At present, the PUWG2000 system is the obligatory geodetic coordinates system in Poland. The railway routes on which the authors made satellite measurements were identified in this system according to the adopted methodology of mobile satellite measurements. With the use of the results based on conducted measurement series, the majority of the geometric layout of tram network in Gdansk as well as of selected railway lines have been recreated [18, 23]. The implemented algorithms are based on the analytical design method and on numerical matrix transformations of homogeneous coordinates [4, 5]. On the other hand, the use of optimization algorithms allowed to effectively identify geometrical parameters, taking into account the admissible speed criteria and the spatial adjustment of the theoretical model of railway line to the measurement signal [24]. As a result of this work, an effective tool was created which can support the design and analysis of the railway lines. Figure 5 presents sample results of calculation with the use of developed algorithms in PUWG 2000 rectangular coordinates system.

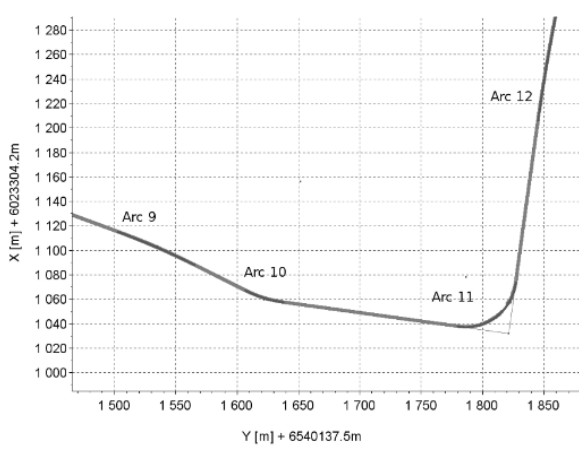

Fig. 5. Identified geometric layout of the measured tram track in the PUWG 2000 system.

Figure 6 presents the result of identification of the horizontal railway arch with parameters: radius of the arc $\mathrm{R}=655 \mathrm{~m}$, length of transition curves $L_{1}=L_{2}=138 \mathrm{~m}$. The differences in the ordinates between the measurement signal and the model geometric layout of the track form the basis of the presented identification results. These differences are calculated in local coordinates systems. In the case of transition curves, the abscissa of this system is tangent to the beginning of the transition curve. The differences for a circular arc are calculated in a system in which the main directions are set symmetrically, i.e. they have the same (absolute) gradient of the line. From the distribution of these differences, it is possible to define the level of identify accuracy (match) of the layout to the measurements and the level of deformation on its length.

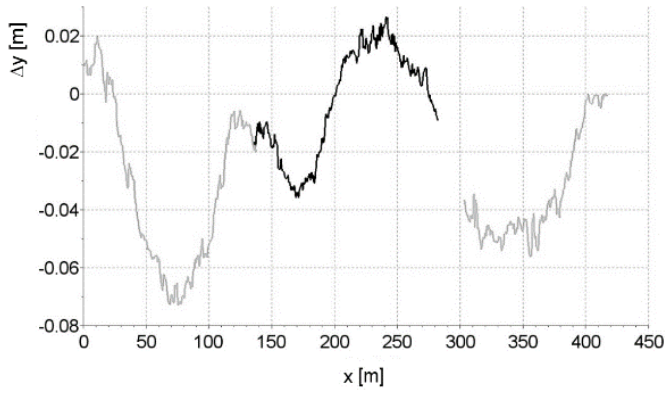

Fig. 6. Distribution of vertical ordinates differences over the length of the evaluated arc. The dark line indicates differences along a circular arc, and light ones - along transition curves.

\section{Conclusions}

The results presented in this paper clearly indicate the growing potential of mobile satellite measurement techniques in the key fields of railway engineering, particularly in the problems of evaluation of the shape of the track axis. This issue belongs to the field of both design and maintenance. The authors, however, do not exclude the use of these measurement methods also in the diagnosis of the railway track, and thus in determining the 
short wave deformation of individual rails in the railway tracks. The achievable, still improving accuracy indicates the legitimacy of continuing the research, so that future assessment of the track layouts could be carried out only in the global reference system, i.e. in relation to the constellation of satellites and reference stations of Realtime GNSS Networks. Such an opportunity would undoubtedly accelerate the measurement process and would make the assessment not entirely dependent on the local control lines and their accuracy (railway geodetic control networks).

\section{References}

1. W. Koc, C. Specht, P. Chrostowski, K. Palikowska, Brit. J. of App. Sci. and Tech., 18, 4, 1-11, (2017)

2. K. Zboinski, P. Woznica, Arch. of Civ. Eng. 63, 1, 181-199, (2017)

3. P. Chrostowski, W. Koc, K. Palikowska, Proc. of ICE - Transp. (Ahead of Print 2017)

4. W. Koc, Math. P. in Eng., 2014, (2014)

5. W. Koc, P. Chrostowski, J. of Transp. Eng. ASCE, 140, 3, 1-8, (2014)

6. Kobryn, Transition curves for highway geometric design, (Springer Int. Pub. AG, 2017)

7. R. Gleba, S. Grulkowski, J. Zariczny, Pol. Marit. Res., 24, 82-88, (2017)

8. T. B. Szwilski, R. Begley, P. Dailey, Z. Sheng, Proceedings of the AREMA, (2003)

9. S. Cellmer, J. Rapinski, M. Skala, K. Palikowska, J. of Surv. Eng. ASCE, 141, 4, 1-24, (2015)

10. Q. Chen, X. Niu, Q. Zhang, Y. Cheng, Navig., 62, 83-93, (2015)

11. Q. Chen, X. Niu, L. Zuo, T. Zhang, F. Xiao, Y. Liu, J. Liu, Sens., 18, 2, (2018)

12. M. Strach, K. Makowska, IEEE Conf.: Baltic Geodetic Congress Geomatics, 28-33, (2016)

13. J. Szczesny, M. Jakimowicz, A. Kwiatkowski, M. Jankowski, Zesz. Nauk. -Tech. SITK RP Odz. Krak., 3, 102, (2013)

14. S. O. Elberink, K. Khoshelham, Rem. Sens., 7, 55655583, (2015)

15. A. Yoshimura, Y. Naganuma, Railway Engineering 2013 - 12th International Conference and Exhibition, (2013)

16. C. Specht, W. Koc, Transp. Res. Proc., 14, 625-634, (2016)

17. C. Specht, W. Koc, P. Chrostowski, Open Eng., 6, 1, $125-135,(2016)$

18. C. Specht, W. Koc, L. Smolarek, A. Grzadziela, J. Szmaglinski, M. Specht, J. of Vibroeng., 16, 6, 30763085, (2014)

19. B. W. Parkinson, Global Positioning System: Theory and Applications, Vol. 1, (Cambridge, 1996)

20. C. Specht, System GPS, (Bernardinum, 2007)

21. Railway Gazette, Pomeranian Metropolitan Railway opens, (2015), available - 18 June, 2018: http://www.railwaygazette.com/news/passenger/sing le-view/view/pomeranian-metropolitan-railwayopens.html
22. W. Koc, C. Specht, P. Chrostowski, K. Palikowska, Arch. of Transp., 24, 3, 307-320, (2012)

23. C. Specht, W. Koc, P. Chrostowski, J. Szmaglinski, Urb. R. Trsns., 3, 1-13, (2017)

24. W. Koc, C. Specht, P. Chrostowski, K. Palikowska, Brit. J.of App. Sci. and Tech., 18, 4, 1-11, (2017) 